\title{
Non-HDL cholesterol predicts coronary heart disease in primary prevention: findings from an Italian a 40-69 year-old cohort in general practice
}

\author{
Il colesterolo non-HDL predice la malattia coronarica \\ in prevenzione primaria: risultati da una coorte italiana \\ di 40-69 anni in medicina generale
}

Anna V. Ciardullo1-3, Luigi Azzolini2, Massimo Bevini2, Tiziano Cadioli2, Paolo Malavasi², Alberto Morellini2, M. Monica Daghio1, Patrizia Guidetti1, Manuela Lorenzetti ${ }^{1}$, Carlo Carapezzi3

RIASSUNTO. Il colesterolo non-HDL predice la malattia coronarica in prevenzione primaria: risultati da una coorte italiana di 40-69 anni in medicina generale. A.V. Ciardullo L. Azzolini, M. Bevini, T. Cadioli, P. Malavasi, A. Morellini, M.M. Daghio, P. Guidetti, M. Lorenzetti, C. Carapezzi.

Scopo. La frazione lipoproteica denominata "colesterolo non-HDL" viene raccomandata come un indice di rischio coronarico (RC) associata alla dislipidemia combinata ed è stata trovata un utile fattore predittivo del rischio coronarico nei pazienti diabetici. Abbiamo studiato l'associazione tra i fattori di RC noti, incluso la colesterolo non-HDL ed una "condizione di RC elevato", cioè un "RC a 5-anni $>15 \%$ " in medicina generale.

Metodi. Abbiamo studiato 4085 individui di età 40-69 anni, 489 diabetici e 3596 non-diabetici, appartenenti ad una coorte opportunistica. Sono state utilizzate le statistiche descrittive, e la regressione logistica multivariata aggiustata per età e sesso per i confronti tra i 2 gruppi.

Risultati. Circa il $12 \%$ dei participanti era diabetico.
I confronti aggiustati per età e sesso hanno mostrato che tutte le variabili erano significativamente peggiori nei diabetici rispetto ai non-diabetici (eccetto fumo, colesterolo totale e rapporto colesterolo totale/HDL). I diabetici avevano un "RC medio a 5-anni" più alto dei non-diabetici $(18.8 \pm 11.9 \%$ vs $7.5 \pm 6.9 \%, P<0.01)$, e una prevalenza quattro volte maggiore di un "RC a 5-anni $>15 \%$ " $(55.4 \%$ vs $11.1 \%, P<0.01)$. Nei diabetici, le variabili associate ad una "condizione di RC elevato" sono: fumo, pressione arteriosa sistolica (PAS) e colesterolemia non-HDL; nei non-diabetici: fumo, PAS, colesterolemia non-HDL e HDL (inversamente).

Conclusioni. Il colesterolo non-HDL - oltre a fumo e PAS - è un forte predittore di una "condizione di RC elevato" sia negli individui diabetici che non-diabetici.

Parole chiave: Cardiopatia ischemica, diabete, lipidi plasmatici, medicina generale.

Monaldi Arch Chest Dis 2004; 62: 2, 69-72.

${ }^{1}$ Local Health Plan for Cardiovascular Disease.

2 GPs on the behalf of "GPs' CV Risk Group".

3 Internal Medicine Hospital Department - Local Health Unit, Modena, Italy.

Correspondence: Dott.ssa Anna Vittoria Ciardullo, MD MSc - Local Health Plan for Cardiovascular Disease - Local Health Unit-Via San Giacomo, 2 - 41100 Carpi (Mo), Italy; e-mail: a.ciardullo@ausl.mo.it

\section{Introduction}

Existing guidelines do take advantage of nonHDL cholesterol as an index of risk associated with combined dyslipidemia, since it circumvents the potential limitation of triglycerides as a mere marker of coronary heart disease (CHD) risk [1].

Non-HDL cholesterol is defined as the difference between total and HDL cholesterol, and represents cholesterol carried on all of the potentially proatherogenic apoprotein B-containing particles (VLDL, IDL, and LDL as well as chylomicron remnants and lipoprotein[a]) [2].
The elevated CHD risk affecting patients with type 2 diabetes has been attributed to the combined dyslipidemia, which may confer a higher magnitude of risk than elevated LDL cholesterol alone [3-4].

Non-HDL cholesterol index has also been found useful in predicting CHD risk in people with diabetes [5].

The aim of the present work was to study the association between known CHD risk factors - enclosed non-HDL cholesterol - and a "high CHD risk condition" among 40- to 69-year-old diabetic and non-diabetic individuals from an opportunistic cohort cared by general practitioners (GPs). 


\section{Methods}

We performed an observational study among 40- to 69-year-old individuals from an opportunistic cohort cared by GPs of an Italian health district adhering to a Local Health Plan for Cardiovascular Disease. In Italy, citizens pay the national health system for a doctor chosen from a list of available GPs, thus implying that everyone are in charge to a GP.

A "diabetic individual" was defined as an "individual treated for diabetes" and/or having a "blood glucose grater than $7.0 \mathrm{mmol} / \mathrm{l}$ (126 $\mathrm{mg} / \mathrm{dl}) "$.

A "high CHD risk condition" was defined as a "5-years CHD risk $>15 \%$ ". We choose the New Zealand coronary risk function [6] - among the other charts available in literature - because of the demonstrated ability of GPs to interpret and applying it easily [7].

We collected data on the risk factors included in the CHD risk function, i.e. age, gender, cigarette smoking, systolic blood pressure (SBP), total and HDL cholesterol. Non-HDL cholesterol and the ratio of total to HDL cholesterol have been calculated.

Cross-sectional descriptive frequencies for $d i$ abetic and non-diabetic individuals have been calculated. Age- and gender- adjusted diabetic vs non-diabetic individuals comparison have also been computed by means of multivariate logistic regression.

\section{Results}

Twenty-three GPs (out of 76) enrolled over a 12 months period 4,085 (out of 37,054 inhabitants) 40-69-year-old individuals. None of them had already sustained a cardiovascular event and $12.0 \%$ had diabetes.

The participants' characteristics and the "5years CHD risk" findings are described in table 1.

All the study variables were significantly worse in diabetic than non-diabetic individuals with the exception of cigarette smoking, total blood cholesterol and the ratio of total to HDL cholesterol). They had a mean "5-year CHD-risk" significantly higher than non-diabetic individuals, and a four-folds prevalence of "5-years CHD risk $>15 \%$ " (table 1).

About $60 \%$ of diabetic - vs $35 \%$ non-diabetic individuals - had a SBP greater than $140 \mathrm{mmHg}$, and $8 \%$ vs $2 \%$ a SBP greater than $160 \mathrm{mmHg}$, respectively $(\mathrm{P}<0.01)$. Diabetic patients had a twice "HDL lower than $1.0 \mathrm{mmol} / \mathrm{l}$ (40 mg/dl)" prevalence $(20 \%$ vs $10 \%, \mathrm{P}<0.01)$, but they showed a lower prevalence of "Total Cholesterol higher than $5.18 \mathrm{mmol} / \mathrm{l}(200 \mathrm{mg} / \mathrm{dl}) "(68 \%$ vs $74 \%, \mathrm{P}<0.01)$. No difference was found in smoking habits between the two groups ( $23 \%$ vs $22 \%, \mathrm{P}=0.89$ ) (table 1). About $3 \%$ of diabetic patients had no CHD risk factors, vs $29 \%$ of non-diabetic individuals $(\mathrm{P}<0.01)$.

As to diabetic individuals, the study variables associated to a "high CHD risk condition" were

Table 1. - Patients' characteristics and 5-years coronary heart disease (CHD) risk (mean $\pm S D)$

\begin{tabular}{|c|c|c|c|}
\hline Variable & $\begin{array}{l}\text { Diabetic Individuals } \\
\text { No. } 489\end{array}$ & $\begin{array}{l}\text { Non Diabetic Individuals } \\
\text { No. } 3596\end{array}$ & P-value \\
\hline Age (years) & $59.1 \pm 7.0$ & $55.7 \pm 8.1$ & 0.001 \\
\hline Male gender $(\%)$ & 57.9 & 43.6 & 0.001 \\
\hline Cigarette smoking (\%) & 23.5 & 21.6 & 0.137 \\
\hline Systolic Blood Pressure [SBP] (mmHg) & $143.5 \pm 12.5$ & $136.1 \pm 12.5$ & 0.001 \\
\hline Blood Total Cholesterol (mmol/l) [mg/dl] & $\begin{array}{l}5.77 \pm 1.11 \\
{[222.8 \pm 43.0]}\end{array}$ & $\begin{array}{l}5.82 \pm 0.93 \\
{[224.9 \pm 36.1]}\end{array}$ & 0.891 \\
\hline Blood HDL Cholesterol (mmol/l) [mg/dl] & $\begin{array}{l}1.32 \pm 0.36 \\
{[51.1 \pm 14.0]}\end{array}$ & $\begin{array}{l}1.47 \pm 0.40 \\
{[56.8 \pm 15.4]}\end{array}$ & 0.003 \\
\hline Blood Non-HDL Cholesterol (mmol/l) [mg/dl] & $\begin{array}{l}4.45 \pm 1.10 \\
{[171.7 \pm 42.3]}\end{array}$ & $\begin{array}{l}4.35 \pm 0.95 \\
{[168.1 \pm 36.9]}\end{array}$ & 0.003 \\
\hline Ratio of Total to HDL Cholesterol & $4.6 \pm 1.3$ & $4.22 \pm 1.3$ & 0.538 \\
\hline $\begin{array}{l}\text { Prevalence of High Blood Cholesterol }(\%) \\
\text { [Total Cholesterol }>5.18 \mathrm{mmol} / \mathrm{l}]\end{array}$ & 68.4 & 74.5 & 0.003 \\
\hline $\begin{array}{l}\text { Prevalence of Low HDL Cholesterol (\%) } \\
\text { [HDL Cholesterol < } 1.0 \mathrm{mmol} / \mathrm{l}]\end{array}$ & 20.1 & 9.9 & 0.001 \\
\hline Prevalence of High SBP $(\%)[\mathrm{SBP}>140 \mathrm{mmHg}]$ & 59.6 & 34.9 & 0.001 \\
\hline 5-years CHD risk (\%) & $18.8 \pm 11.9$ & $7.5 \pm 6.9$ & 0.001 \\
\hline $\begin{array}{l}\text { Prevalence of 'high' CHD risk (\%) } \\
\text { [5-years CHD risk >15\%] }\end{array}$ & 55.4 & 11.1 & 0.002 \\
\hline
\end{tabular}

a age- and gender-adjusted diabetics vs non diabetics comparison. 
Table 2. - Predictors of a "5-year CHD-risk grater than 15\%"

\begin{tabular}{lll}
\hline Variable & $\begin{array}{c}\text { Diabetic Individuals } \\
\text { No. } \mathbf{4 8 9} \\
\text { Exp beta }(95 \% \text { CI })\end{array}$ & $\begin{array}{c}\text { Non Diabetic Individuals } \\
\text { No. 3596 } \\
\text { Exp beta }\end{array}$ \\
\hline Cigarette smoking & $9.20(4.63$ to 18.26$)$ & $10.56(7.73$ to 14.43$)$ \\
\hline Systolic Blood Pressure & $1.10(1.07$ to 1.12$)$ & $1.07(1.06$ to 1.08$)$ \\
\hline Blood Total Cholesterol & $1.21(0.68$ to 2.15$)$ & $1.32(0.96$ to 1.82$)$ \\
\hline Blood HDL Cholesterol & $0.13(0.01$ to 1.21$)$ & $0.11(0.03$ to 0.47$)$ \\
\hline Blood Non-HDL Cholesterol & $1.63(1.34$ to 1.99$)$ & $1.89(1.66$ to 2.15$)$ \\
\hline Ratio of Total to HDL Cholesterol & $1.39(0.69$ to 2.80$)$ & $1.31(0.93$ to 1.85$)$ \\
\hline a age- and gender-adjusted. & &
\end{tabular}

cigarette smoking, systolic blood pressure, and non-HDL blood cholesterol levels, whereas total and HDL cholesterol, and the ratio of total to HDL cholesterol did not (table 2).

As to non-diabetic individuals, the study variables associated to a "high CHD risk condition" were cigarette smoking, systolic blood pressure, and HDL (inversely) and non-HDL blood cholesterol levels, whereas total and the ratio of total to HDL cholesterol did not (table 2).

\section{Discussion}

Cross-sectional and prospective studies have demonstrated the value of non-HDL cholesterol as an index of CHD risk across different populations, including Europeans [8-9].

Non-HDL cholesterol appears to track with multiple CHD risk factors in U.S. ethnic minorities that are disproportionately affected by diabetes [10].

Such use of non-HDL cholesterol has been proposed for diabetic patients as well as the general population. However, it has been pointed out that for non-HDL cholesterol to replace LDL cholesterol as the primary lipid target for the general population, strong evidence of its superiority will be needed [11].

At present, such evidence is not yet available. Nevertheless, the NCEP has clearly acknowledged the importance of non-HDL cholesterol for patients with hypertriglyceridemia, which may include those with type 2 diabetes [1].

Recent findings [5] have shifted the weight of evidence further in favour of the primacy of nonHDL cholesterol specifically for patients with type 2 diabetes. This study also report that the ratio of total to HDL cholesterol was a strong predictor of CHD, although the confidence intervals again overlapped significantly. Thus, in the search for the optimum index of risk, the ratio of total to HDL cholesterol should also be taken into account.

We are aware that our findings might be affected by a selection bias since - by indication we did not use a random sample, but an opportunistic cohort of individuals assisted by GPs.
Nevertheless, we thought that our study might have provided some interesting information.

In particular, our findings seemed to confirm the primacy of non-HDL cholesterol for diabetic patients. In fact, in diabetic individuals we found that non-HDL blood cholesterol levels was associated to a "high CHD risk condition", whereas total and HDL cholesterol, and the ratio of total to HDL cholesterol did not (table 2). Furthermore, the calculation of non-HDL cholesterol value is very simple and suitable to the busy GPs.

In conclusion, we found that cigarette smoking, systolic blood pressure, and non-HDL cholesterol levels strongly predicted a "high CHD risk condition" both in diabetic and non-diabetic individuals.

\section{Abstract}

Objects. Non-HDL cholesterol is now recommended as an index of risk associated with combined dyslipidemia, and it has also been found useful in predicting coronary heart disease (CHD) risk in patients with diabetes. We studied the association between known CHD risk factors, enclosed non-HDL cholesterol, and a "high CHD risk condition", i.e. a "5-years CHD risk $>15 \%$ " in general practice.

Methods. We studied 4,085 40-69 year-old diabetic (no. 489) and non-diabetic (no. 3,596) individuals from an opportunistic cohort. Cross-sectional descriptive statistics, and age-and genderadjusted multiple logistic exponential betas have been calculated.

Results. About $12 \%$ of the participants had diabetes. Age- and gender-adjusted comparison showed that all the study variables were significantly worse in diabetic vs. non-diabetic individuals (except cigarette smoking, total blood cholesterol and the ratio of total to HDL cholesterol). They had a mean "5-year CHD-risk" significantly higher than non-diabetic individuals $(18.8 \pm 11.9 \%$ vs $7.5 \pm 6.9 \%, P<0.01)$, and a four-folds prevalence of "5-years CHD risk $>15 \%$ " (55.4\% vs $11.1 \%, P<0.01)$. As to diabetic individuals, the study variables associated to a "high CHD risk condition" were cigarette smoking, systolic blood 
pressure, and non-HDL blood cholesterol levels. As to non-diabetic individuals cigarette smoking, systolic blood pressure, and HDL (inversely) and non-HDL blood cholesterol levels were associated to a "high CHD risk condition".

Conclusions. Non-HDL cholesterol - and cigarette smoking and systolic blood pressure strongly predicted a "high CHD risk condition" both in diabetic and non-diabetic individuals.

Keywords: Coronary heart disease, opportunistic cohort, diabetes, blood lipids, family medicine.

Addendum: We thanks the members of the "GPs' CV Risk Group" who should be considered co-authors: Bacchelli M, Bellodi C, Beltrami AC, Carretti G, Di Fiore A, Feltri G, Frignani A, Gaglianò G, Gazzani G, Loscalzo G, Losi A, Mantovani L, Pavarotti V, Prandi B, Ribaldi A, Rosselli C, Tirelli G, Veratti M, Vincenzi A.

Acknowledgements: We are grateful to all the study participants. This work has been supported by the Carpi's Health District of Local Health Unit in Modena. No competing interests to declare.

\section{References}

1. Expert Panel on Detection, Evaluation, and Treatment of High Blood Cholesterol in Adults. Executive summary of the third report of the National Cholesterol Education Program (NCEP) Expert Panel on Detection, Evaluation, and Treatment of High Blood Cholesterol in Adults (Adult Treatment Panel III). JAMA 2001; 285: 2486-2496.

2. Abate N, Vega GL, Grundy SM. Variability in cholesterol content and physical properties of lipoproteins containing apolipoprotein B-100. Atheroscler 1993; 104: 159-171.

3. Garg A, Grundy SM. Management of dyslipidemia in NIDDM. Diabetes Care 1990; 13: 153-169.

4. Assmann G, Schulte H. Relation of high-density lipoprotein cholesterol and triglycerides to incidence of atherosclerotic coronary artery disease (the PROCAM experience). Am J Cardiol 1992; 70: 733-737.

5. Lu W, Resnick HE, Jablonski KA, Jones KL, Jain AK, Howard WJ, Robbins DC, Howard BV. Non-HDL cholesterol as a predictor of cardiovascular disease in type 2 diabetes: the Strong Heart Study. Diabetes Care 2003; 26: 16-23.

6. Jackson R. Updated New Zealand cardiovascular disease risk-benefit prediction chart. BMJ 2000; 320: 709710.

7. Isles CG, Ritchie LD, Murchie P, Norrie J. Risk assessment in primary prevention of coronary heart disease: randomised comparison of three scoring methods. $B M J$ 2000; 320: 690-691.

8. Menotti A, Kromhout D, Nissinen A, Giampaoli S, Seccareccia F, Feskens E, Pekkanen J, Tervahauta M. Short-term all-cause mortality and its determinants in elderly male populations in Finland, the Netherlands, and Italy: the FINE Study. Prev Med 1996; 25: 319326.

9. Lehto S, Ronnemaa T, Haffner SM, Pyorala K, Kallio V, Laakso M. Dyslipidemia and hyperglycemia predict coronary heart disease events in middle-aged patients with NIDDM. Diabetes 1997; 46: 1354-1359.

10. Gardner CD, Winkleby MA, Fortmann SP. Population frequency distribution of non-high-density lipoprotein cholesterol (Third National Health and Nutrition Examination Survey [NHANES III], 1988-1994). Am J Cardiol 2000; 86: 299-304.

11. Grundy SM. Non-high-density lipoprotein cholesterol level as a potential risk predictor and therapy target. Arch Int Med 2001; 161: 1379-1380.

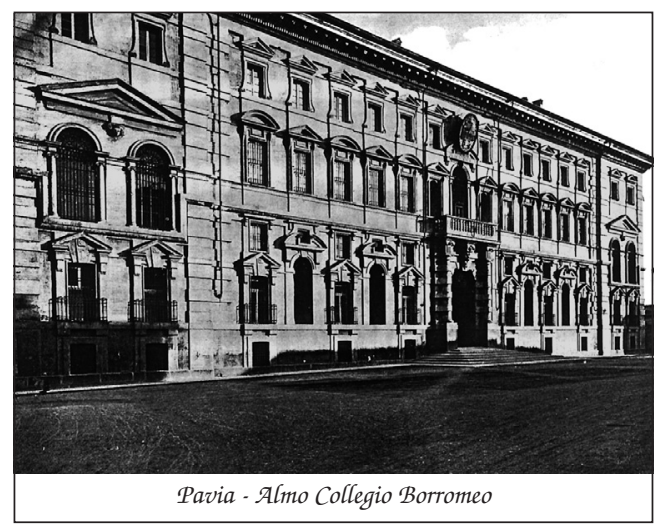

